\title{
A CONSTRUÇÃO DO CAMINHO DO VÍNCULO MÃE ADOLESCENTE / BEBÊ PRE-TERMO
}

\author{
THE CONSTRUCTION OF THE PATHWAY TO THE BOND THAT \\ LINKS THE ADOLESCENT MOTHER TO HER PRETERM BABY
}

\section{Susana Elena Delgado ${ }^{1}$}

DELGADO, S. E. A construção do caminho do vínculo mãe adolescente / bebe pré-termo. Rev. Bras. Cresc. Desenv. Hum., São Paulo, 12(1), 2002.

Resumo: A maternidade precoce traz consigo riscos para a mãe adolescente e seu bebe. Entre estes riscos, a prematuridade é vista como um dos possíveis fatores de dificuldade de vinculação da díade mãe-adolescente e bebe pré-tenno. Este artigo pretende apresentar um estudo de caso que descreve a construção do vínculo de uma mãe adolescente e seu bebé prematuro, através de intervenções da equipe de saúde e, em especial da fonoaudiologia, no incentivo ao aleitamento matemo.

Palavras-chave: interação mãe-bebê; aleitamento materno; fonoaudiologia; bebés pré-termo; adolescência.

\section{INTRODUÇÃO}

No início da vida, o bebé tem a mãe como um prolongamento de si mesmo. Segundo BOWLBY (1990),"os psicanalistas são unanimes em reconhecer a primeira relação humana de uma criança como a pedra fundamental sobre a qual se edifica a sua personalidade”. Este primeiro vínculo, geralmente com a mãe, é denominado apego. Vários pesquisadores têm-se dedicado a estudar em profundidade este tema (BRAZELTON, 1988; KLAUS \& KLAUS, 1989; MAZET \& STOLERU, 1990; SPITZ, 1996; GUEDENEY \& LEBOVICI, 1999; CARON, 2000) e, embora, não haja consenso à respeito da natureza deste vínculo, a maioria dos autores concorda que dele depende o desenvolvimento físico e psicológico adequado da criança.

O principal foco de interação entre os pais e os filhos, nos primeiros anos de vida, é, em geral, a alimentação. Esta se inicia nas primeiras horas de vida com a amamentação. O toque, o calor corpo- ral, o contato visual e auditivo que a amamentação propicia constituem importante estirnulacão afetiva e cognitiva (LAWRENCE, 1996). Este é um período de grande aprendizagem tanto para a mãe quanto para a criança que, conforme evolue, pode determinar futuros problemas de interação familiar (RAMOS \& STEIN, 2000).

A prematuridade de uma criança não constitui em si uma condição prejudicial para o estabelecimento do vínculo; porém, do ponto de vista estatístico, os prematuros são super representados na população de crianças vítimas de maus tratos e atrasos de desenvolvimento de etiologia nãoorganica (MAZET \& STOLERU, 1990).

Numerosos estudos têm acompanhado díades de mães e bebés prematuros encontrando dificuldades no estabelecimento do vínculo inicial uma vez que o nascimento de uma criança prematura e, notoriamente, em caso de baixo peso ao nascer, é um choque afetivo, que pode ser vivido de maneira dolorosa e traumatizante

1 Fonoaudióloga, docente da Universidade Luterana do Brasil, Porto Alegre-RGS; E-mail: sudel.ez@terra.com.br 
(BRAZELTON, 1988; MAZET \& STOLERU, 1990; CRESTI \& LAPI, 1997; DRUON, 1997; WIRTH, 2000). Poder-se-ia dizer que o parto é prematuro para o bebê e para a mãe. Este bebê pré-termo não corresponde às expectativas dos pais que deverão realizar, além do luto pelo filho imaginário, o luto do bebê pré-termo real que corre risco de vida e está com sua morte anunciada (WIRTH, 2000). A não concretização do filho imaginário e perfeito interrompe a relação mãebebề e gera vários sentimentos de depressão, culpa, rejeição e até hostilidade. A aceitação do bebê real é um processo difícil que depende da história individual da mãe, das relações com seus próprios pais e das condições psicológicas que ela apresenta (SPITZ, 1996).

Dentro desse cenário, a adolescente que engravida tem sua crise do ciclo vital sobrecarregada com outro processo crítico na vida de uma mulher: a gravidez. Segundo VIÇOSA (1997), o perfil mais freqüentemente encontrado entre as adolescentes gestantes é o desamparo emocional, um estado de ansiedade e sentimentos ambivalentes com respeito ao bebê. Porém, o fato de a mãe ser adolescente não tem uma relação direta com fatores de risco na gravidez e, sim, com a gravidez não ser desejada e/ou procurar tardiamente o pré-natal.

A gestação para a adolescente nem sempre é vista negativamente. As adolescentes de nível sócio-econômico mais baixo passam a ver a gravidez como uma forma de status social e de aceder mais rápido ao nível de autonomia adulto (VIÇOSA, 1997). A mesma autora refere que, quanto mais cedo a mãe adolescente for motivada a desenvolver uma interação positiva com seu bebê, mais chances terá de se vincular fortemente com o filho e exercer sua função materna.

Dentro da minha prática clínica, numa UTI Neonatal, tenho acompanhado muitos casos de mães adolescentes com filhos prematuros, onde as questões apresentadas acima aparecem com muita freqüência. Um dos sinais das alterações na relação mãe-bebê se evidenciam nas dificuldades de amamentação.

Porém, existem casos de mães adolescentes que transformam este momento de conflito em momentos de aprendizagem e superação. Este artigo pretende apresentar um estudo de caso que descreve a construção do vínculo de uma mãe adolescente e seu bebê prematuro.

\section{REFERENCIAL TEORICO}

A Organização Mundial de Saúde (OMS), desde 1977, considera como pré-termo todo recém nascido vivo de gestação inferior a 37 semanas ou 259 dias, sempre a partir da última data da menstruação até a data do parto. A prematuridade é um fator que está associado ao aumento da morbidade e mortalidade neonatal, especialmente em bebês que nascem com menos de 1500 gramas, podendo levar a seqüelas que irão influenciar o desenvolvimento da criança e estão relacionadas a processos biológicos, ambientais e cognitivos (MIURA, 1991; HERNANDEZ, 1996; HALPERN, 2000). Os efeitos da interação entre os potenciais biológicos e ambientais com processos afetivos e psicossociais podem ser negativos (por exemplo: a associação entre a pobreza e o baixo peso ao nascer) ou positivos (por exemplo: aleitamento materno como proteção às infecções). Para VAZ (1989), os recémnascidos pré-termo correspondem a um grupo de risco elevado para lesões hipóxicas que levam à paralisia cerebral, retardo mental e outros, reduzindo a habilidade para adaptação social, física e psicológica.

Esses bebês apresentam algumas desvantagens anatômicas, somadas à imaturidade, que podem interferir na sucção adequada. A ausência ou diminuição de gordura nas bochechas ("sucking pads" ou coxins) leva à instabilidade da mandíbula e à falta de vedamento labial adequado. A movimentação da língua pode se apresentar não funcional e sem canolamento, determinando escape de leite. Por outro lado, o padrão extensor apresentado por estes bebês dificulta a sucção efetiva, uma vez que a extensão gera a respiração oral, aumenta o risco de aspiração do leite e leva à fadiga rapidamente (ARVEDSON \& BRODSKY, 1993).

O aspecto emocional do aleitamento é referido por vários autores (BRAZELTON, 1988; SPITZ, 1996; LAWRENCE, 1996; WINNICOTT, 1999; XAVIER, 1998), como a base do desenvolvimento psicológico do apego, sendo indicado também como o início da comunicação não-verbal entre a mãe e o bebê. Ambas questões apresentam-se fundamentais para o desenvolvimento adequado da personalidade. As mães de prematuros não concretizam, na vida real, o filho imaginário e perfeito. A quebra da relação mãe-bebê poderá gerar vários sentimentos de ambivalência e culpa. Todas estas dificuldades podem ser maiores se a mãe é uma adolescente.

A adolescência é um período de transição entre a infância e a idade adulta que envolve muitas mudanças físicas, cognitivas e psicossociais. Este período dura aproximadamente uma década (dos 12 aos 20 anos), sendo considerado seu início na puberdade (processo biológico que leva à maturidade sexual) (PAPALIA \& OLDS, 2000). 
O grande avanço da difusão, através dos meios de comunicação, de novos padrões de comportamento e valores tem influenciado as práticas da sexualidade do adolescente, levando-as a ocorrer cada vez mais cedo. Isto parece se refletir na incidência cada vez maior de gestações em adolescentes (VIÇOSA, 1997).

As gestações na adolescência, muitas vezes, têm o risco de produzir bebês que, além de prematuros, apresentam-se com muito baixo peso ao nascer (menos de 1500 gramas). Isto acontece porque, geralmente, as mães adolescentes são pobres, com baixo nível de instrução, não se alimentam bem, recebem uma assistência pré-natal inadequada ou, por vezes, nenhuma (PAPALIA \& OLDS, 2000). Entretanto, nem sempre os aspectos econômicos são responsáveis pelos partas prematuros: um estudo, realizado em Utah, com 134.000 meninas e mulheres, concluiu que mães entre 13 e 19 anos tinham maior probabilidade de ter bebés de baixo peso natal se comparadas às mães de 20 a 24 anos, independente de seu grau de instrução, estado civil e assistência pré-natal (FRASER, BROCKERT \& WARD, 1995). Segundo os autores, o baixo peso estaria associado ao fato da adolescente estar em crescimento, ainda competindo pelos nutrientes com o bebê.

Outro fator importante na gravidez da adolescente é estas meninas precisarem desenvolver habilidades para cuidar de um bebê, muitas vezes frágil e doente. Segundo VIÇOSA (1997), quanto mais cedo forem motivadas a desenvolver afeto pelos seus bebês, melhor será o vínculo mãe-bebê. Um atendimento por equipe multidisciplinar nesse período se faz necessário a fim de dar o tempo para a mãe, o companheiro e a família de se recuperarem do impacto de um nascimento prematuro e dar suporte para a adolescente sentir-se competente para cuidar do seu filho (VIÇOSA, 1997; GUEDENEY \& LEBOVICI, 1999).

Todos os profissionais envolvidos no atendimento do bebê têm que estar alertas no andamento da relação mãe-bebê: com quê freqüência o bebê é visitado? quais as preocupações desses pais? conseguem falar de suas dúvidas? acompanham a recuperação do filho? percebem mudanças no bebé?

Muitas vezes o que essas mães precisam é de um espaço de escuta, onde não só coloquem suas angústias mas, também, suas expectativas positivas sobre esse filho que não era o esperado. Como profissionais de saúde temos que participar na reconstrução de uma história que foi abruptamente interrompida, ajudando os pais a re-significar o nascimento do filho prematuro.

\section{MÉTODO}

Entre os vários casos atendidos, este foi selecionado por ilustrar muito bem a possibilidade de uma mãe adolescente vir a se vincular, de uma maneira adequada, ao seu bebê prematuro.

Foi realizado um estudo de caso individual, numa abordagem qualitativa, com o objetivo de compreender os dados coletados e ampliar o conhecimento do assunto pesquisado (GOMES, 1997; GOLDIM, 2000).

Para tanto, foi realizada uma entrevista não estruturada, de enfoque fenomenológico, com uma questão aberta que investiga o que significa amamentar um bebê prematuro para a mãe adolescente. Dentro deste enfoque, pretende-se não explicar um fenômeno mas compreendê-lo através da consciência do fato vivido pelo seu ator (CARVALHO, 1987). A entrevista, segundo MINAYO (1992, p. 107-108), é uma "conversa a dois, feita por iniciativa do entrevistador, destinada a fornecer informações pertinentes para um objeto de pesquisa”. Porém, a entrevista fundamentada no método fenomenológico não submete ao entrevistado a uma análise conceitual ou classificadora mas busca-se, através da compreensão profunda de seu discurso, a efetivação da consciência de si, que leva à autodeterminação (CARVALHO, 1987).

A entrevista durou aproximadamente 45 minutos e foi gravada.

Para proceder à análise foi usada a técnica de análise de conteúdos, numa forma de análise temática que busca descobrir os núcleos de sentido presentes numa comunicação, os quais revelam significado em relação ao objeto em estudo (MINAYO, 1992). Segundo GOMES (1997), a análise de conteúdo é realizada utilizando as seguintes fases de análise: pré-análise (ordenação dos dados), exploração do material (classificação dos dados), tratamento dos resultados obtidos e interpretação (articulação entre os dados e os referênciais teóricos utilizados no estudo).

\section{DESVELANDO O CAMINHO DA CONSTRUÇÃO DO VÍNCULO}

Na entrevista com M, realizada após assinar o consentimento para participar do estudo, a mãe pareceu disposta e receptiva para falar de sua experiência. Desde os momentos inicias, M dá uma conotação positiva à experiência da maternidade quando diz:

"Desde que tive as dores, eu me senti maisforte... Para lutarpelas coisas que eu quero, porque agora tenho ele”. 
Pergunto se lembra como foi a primeira mamada, ao que prontamente responde:

“.... eu comecei a rir. Foi muito bom e ao mesmo tempo me deu um ataque de rico.... Era uma coisa meio estranha. Mas foi bom, eu senti ele. Eu gostava porque ficava pertinho dele. Porque eu queria passar para ele que eu estava do lado dele”.

Várias mulheres relatam a primeira sensação do ato de alimentar como estranha. Mesmo assim, para $\mathrm{M}$, a estranheza inicial deu ensejo ao sentimento de vinculação real com o bebê ("eu senti ele..., eu estava do lado dele.”).

M relata que a bolsa rompeu quase duas semanas antes do bebê nascer e da sua angústia quando viu $\mathrm{G}$ tão pequeno nascer:

“.... quando ele nasceu eu vi ele tão pequeninho.... eu achei que não ia sobreviver. Eu não quis nem olhar muito, nem tocar, para mim não me apegar... Só quando o vi na incubadora, vi que estava meIhorando, ele me passou força. Então pensei. eu tenho que passar para ele que eu estou aqui."

Este aspecto de sentimentos ambivalentes de apego e rejeição são bem descritos na literatura. Para BRAZELTON (1988), existe um sistema de feedback recíproco na relação mãe-bebê, modelando a resposta do adulto. Este sistemapropicia o sentimento de reciprocidade, identificação e da interação bem sucedida. A partir deste início de comunicação, a mãe sente-se mais competente para compreender as necessidades do filho e o desejo de cumprir sua função materna surge com força, permitindo uma sintonia cada vez mais harmoniosa. M relata esses sentimentos desta forma:

“Nos primeiros dias, ele abriu a boquinha querendo mamar... Então, eu tocava nele de um jeito diferente de quem cuidava dele para ele saber que era eu. Ele sabe que sou eu só com o toque da minha mão..."

Para a mãe poder realizar os cuidados do bebê precisa haver uma identificação com o filho. Segundo CARDOSO (1995, p. 631) “o cuidado materno implica, inicialmente, que a mãe esteja identificada com o filho e, se isso não ocorrer, ela não perceberá as necessidades do mesmo”. Esse processo leva algum tempo e ajuda na construção da competência materna para cuidar o bebê e acelerar a recuperação dele; M nos conta como ela viu a recuperação de G:
"Noutro dia da internação C saiu do oxigênio, o que já foi uma melhora, no outro dia foi para a UTI 2 (sala de cuidados semiintensivos). Foi um dia após o outro que elefoi melhorando...”.

A recuperação gradativa do bebê é acompanhada pela mãe com preocupação e esperança. Muita desta esperança é passada pelos profissionais que cuidam do bebê ao prestar-lhes cuidados com afeto e respeito. A segurança que a mãe precisa para poder suportar a hospitalização prolongada e a separação estão na confiança que a família deposita nos profissionais que cuidam do seu bebê doente. M consegue colocar esta vivência com estas palavras:

“Eu já vim ao hospital sabendo que eu iria embora e ele ia ficar. Todo dia eu vou com isso... Só que como cuidam bem dele e passam segurança para mim, eu vou um pouco mais tranqüila... Mas já fazem 40 dias....".

O espaço que os profissionais proporcionam para a mãe se sentir necessária para o bebê também ajuda a percorrer o caminho da hospitalização com mais confiança. Mesmo os bebês que não podem ser alimentados ao seio recebem o leite materno que a mãe é incentivada a esgotar diariamente no hospital ou em casa. M nos conta o que significava trazer o leite materno de casa:

"Quando eu tirava o leite em casa, eu pensava: é como se eu estivesse cuidando dele agora... ".

A amamentação é uma das bases para a construção dasaúde mental do ser humano, uma vez que, ocorrendo adequadamente, estabelece um ambiente facilitador, no qual as interações naturais do bebê com o meio cooperam para desenvolver plenamente o potencial genético (WINNICOTT, 1999). Este autor refere que a maior parte das dificuldades de alimentar o bebê decorre dos problemas que a mãe tem inicialmente em adaptar-se às necessidades do filho.

“O G pegou o seio na primeira vez... Só depois teve algumas dificuldades porque era preguiçoso, tinha sono e não sugava... Ele começou mamando 5 minutos, 10, foi para 15 e agora mama 45 minutos....”.

Outro momento crítico para os pais é o da alta que, segundo ^BRAZELTON (1988), é um momento no qual eles se deparam com a alegria 
de terminar uma jornada longa e desgastante no hospital e, por outro lado, com o medo de levar o bebê frágil para casa. Para M, a proximidade da alta foi vivenciada com muita expectativa e um pouco de decepção porque não aconteceu no dia previsto:

"Segunda-feira, eu vim com as coisinhas dele... A doutora tinha dito que ia ter alta. Ai, cheguei, foi o pior dia. Arrumei tudo esperando ele... daí eu chego em casa e ele não veio... Isso foi o pior.. ".

Talvez o mais dificil da espera da alta seja que a decisão está sempre fora do alcance dos pais. Nada do que eles possam fazer vai acelerar as condições de alta. Âs vezes os próprios médicos não possuem todas as respostas e os critérios são de difícil entendimento para os pais (CUNHA, 2000).

O período de hospitalização coloca os pais e, especialmente a mãe, numa situação de crise, que muitas vezes leva à reflexão sobre vários aspectos da vida pessoal, sendo percebido como uma experiência que pode modificar valores, sentimentos e capacidades (CUNHA, 2000).

"Eu estou vendo o mundo diferente. Quando minha mãe falava as coisas, agora eu sei que é isso mesmo. Eu tenho medo do meu filho fcar nesse mundo.... Eu tenho que ser forte para poder ajudá-lo... Antes eu era muito dependente dos outros, hoje se tiver que voltar sozinha à meia-noite, eu volto....".

Esta etapa de hospitalização pode ser bem aproveitada pela mãe quando a equipe consegue dar espaço para ela aprender os cuidados especiais que, às vezes, o bebê precisa. $\mathrm{M}$ comenta como ela conseguiu transformar o tempo de hospitalização em um tempo de amadurecimento e preparação para a maternidade:

"Se eu tivesse ganho ele com nove meses e agora eu estando em casa, não teria tanta experiência como tenho hoje... Porque eu fiquei aqui não só para estar com ele mas para aprender... Que nem o primeiro banho, eu dei nele, aprendi a tocar direitinho nele, aprendi a não ter medo de tocar... Todos os cuidados eu aprendi aqui..."

A mãe, ao permanecer junto do bebé no hospital, ajuda na recuperação construtiva dobebê. Segundo CASTRO NETO (1995), a presença e competência da mãe é tão importante para a so- brevivência do bebê quanto o alimento. Mas, para que esta mãe consiga alcançar este objetivo, também precisa de apoio tanto da equipe quanto da família. Segundo MILES, CARISON \& FUNK (1996), o pai do bebê aparece como a figura de apoio da mãe mais freqüente. Embora, geralmente, menos presente no hospital, a mãe sente-se mais segura quando o companheiro divide as preocupações e expectativas com ela.

"Ele (o pai do bebê), desde o começo queria... Eu fiquei não querendo porque achei que era muito nova... Mas ele me disse vamos ficar juntos, morar juntos... Ele trabalha em dois serviços para poder nos manter. Quando ele pode vem aqui, às vezes ele deixa de almoçar para ver ele. Ele está todo bobo com o C... Ele falou que quer ser um pai presente”.

Pergunto para $\mathrm{M}$, o que mais ela gostaria de dizer sobre esta experiência da maternidade e ela me responde:

\begin{abstract}
"Mesmo sendo nova, eu sei que tenho o mesmo amor de uma mãe de 30 anos que ganhe nenê, agora. Eu sei que vou conseguir cuidar dele, eu sei que tenho a mesma força...".
\end{abstract}

\section{CONSIDERAÇÕES FINAIS}

Ao descrever e discutir este caso, refletimos sobre o risco que corre a relação mãe adolescente e bebê pré-termo. A adolescente que gera um filho pre-termo pode vivenciar uma situação muito estressante e de muito risco, tanto para ela quanto para o bebê. A literatura a este respeito traz muitos exemplos dos efeitos deletérios de uma maternidade precoce mal conduzida.

Porém, através da nossa prática, podemos observar que intervenções precoces da equipe de saúde podem levar à supuração desta situação, propiciando a livre expressão c os sentimentos destas mães. Para poder ajudá-las, os profissionais devem identificar suas necessidades e promover o vínculo da mãe com o bebê, dando o suporte necessário para a adolescente desenvolver sua fimção materna.

A fonoaudiologia, de forma integrada com a equipe multidisciplinar, deve participar dos programas de incentivo ao aleitamento materno com mães adolescentes, como uma forma de facilitar o vínculo, considerando este ser um período critico e influir diretarnente na qualidade de vida e no futuro desenvolvimento do bebê, inclusive da comunicação oral e nas 
futuras relações afetivas. A avaliação da função motora oral e de alimentação abarca não só a habilidade motora da criança, mas também os fatores externos que podem interferir, como o meio onde esta é realizada e a interação mãebebê (XAVIER, 1998).

Habilitar um bebê a sugar o seio é, nos casos de bebês prematuros, dar-lhes a oportunidade de "sugar" a vida, escapar da morte física ou emocional. A construção do vínculo, nestes casos, é um caminho cheio de dificuldades, no qual as mães, principalmente adolescentes, precisam de acolhimento para superar a angústia, as dúvidas, a solidão e a falta de confiança nas suas próprias condições de cuidar o filho.

Muitas vezes, a falta de um profissional preparado para realizar uma escuta cuidadosa, tentando compreender aquilo que a mãe está dan- do a ver, não facilita a construção deste pnmeiro vínculo, fundamental para a saúde mental e fisica do bebê. O fonoaudiólogo, como profissional dos distúrbios da comunicação, pode ser a ponte entre a mãe e a equipe e entre a mãe e o seu bebê, intervindo de forma moduladora com os outros profissionais e nos primeiros “diálogos” prélingüísticos da díade.

Acolhendo a mãe mostramos o caminho para o bebê ser acolhido. Restabelecendo a unidade da díade, através da amamentação, favorecemos o desabrochar da mãe intuitiva e empática com seu bebê.

O caminho que $\mathrm{M}$. percorreu nos mostra claramente que risco não é destino. Cabe a nós, como profissionais, atuar com compreensão, delicadeza e empatia propiciando, assim, a vitóna da vida em todas suas possibilidades.

\begin{abstract}
Precocious maternity brings about risks for lhe adolescent mother and her baby. Among these risks, prematurity is seen as one of lhe reasons for lhe troubles found in lhe adolescent mother and lhe preterm baby bonding. This article intends to present a case study that describes the construction of the bond between an adolescent mother and her preterm baby, through the interventions of the health team, specially the speech pathology and audiology, in promoting breastfeeding.
\end{abstract}

Key-words: motherbaby interaction; breastfeeding; speech pathology and audiology; preterm babies; adolescent mother.

\section{REFERENCIAS BIBLIOGRÁFICAS}

ARVEDSON, J.;BRODSKY, L. Pediatric swallowing and feeding: assessment and management. San Diego, Califórnia: Singular Publising Group, Inc., 1993.

BOWLBY, J. Apego. A natuureza do vínculo. São Paulo: Martins Fontes, 199(). p. 192.

BRAZELTON, T. O desenvolvimento do apego. Porto Alegre: Artes Médicas, 1988. p. 21.

CARDOSO, F. S. Maternagem. Acta Médica, 1: 631-635, 1995.

CARON, N. A. (Org.). A relação pais-bebês, da observação à clínica. São Paulo: Casa do Psicólogo, 2000. p. 232.

CARVALHO, A. S. A Metodologia da entrevista, uma abordagem fenomenológica. Rio de Janeiro: Agir, 1987. p. 93.

CASTRO NETO, A. Mãe e filho: um abraço que começa no útero. Pediatria Moderna, 31 (5): 837-838, ago. 1995.

CRESTI, L.; LAPI, 1. O esboço da relação mãe bebê e a instituição hospitalar: díade ou tríade? In: LACROIX, M.; MOYMANRANT, M. (Org.). A observação de bebês. Os laços do encantamento. Porto Alegre: Artes Médicas, 1997. p.149-162.
CUNHA, L. M. Recém-nascidos hospitalizados: a vivência dos pais. Porto Alegre, 2000. [Dissertação de Mestrado - Escola de Enfermagem da Universidade Federal do Rio Grande do Sul]. p. 110.

DRUON, C. Como o espírito vem ao corpo em crianças, em UTI neonatal. In: LACROIX, M.; MOYMANRANT, M. (Org.). A observação de bebês. Os laços do encantamento. Porto Alegre: Artes Médicas, 1997. p. 139- 148.

FRASER, A. M.; BROCKERT, J. E.; WARD, R. $H$. Associaton of young maternal age with adverso reproductive outcomes. The New England Journal of Medecine, 332(17): 11131117, 1995.

GOLDIM, J. R. Manual de iniciação à pesquisa em saúde. Porto Alegre: Dacasa Editora, 2000.

GOM ES, R. A análise de dados em pesquisa qualitativa. In: MINAYO, M.C. (Org.). Pesquisa social: teoria, método e criatividade. Petrópolis, Rio de Janeiro: Vozes, 1997.

GUEDENEY, A.; LEBOVICI, S. Intervenções psicoterápicas pais/bebês. Porto Alegre: Artes Médicas Sul, 1999. p. 158.

HALPERN, R.; GIUGLIANI, E; VICTORA, C.; BARROS, F.; HORTA, B. Fatores de risco para suspeita de atraso no desenvolvimento 
neuropsicomotor aos 12 meses de vida. Jornal de Pediatria, 76(6): 421-428, 2000.

HENANDEZ, A. M. Atuação fonoaudiológica em neonatologia: uma proposta de intervenção. In: ANDRADE, C. R. F. Fonoaudiologia em berçário normal e de risco. São Paulo: Editora Lovise, 1996. p.43-98.

KLAUS, M.; KLAUS, R. O surprendente recémnascido. Porto Alegre: Artes Médicas, 1989.

LAWRENCE, R. Impacto psicológico da lactância materna. In: LAWRENCE, R. La lactancia materna. Un guia para la profesión médica. Madrid: Mosby/Doymalibros, 1996. p. l 83205.

MAZET, R; STOLERU, S. Situações clínicas freqüentes. In: MAZET, P.; STOLERU, S. Manual de psicopatologia do recém-nascido. Porto Alegre: Artes Médicas, 1990. p.263.

MILES, M.; CARLSON, J.; FUNK, S. Sources of support reported by mothers and fathers of infants hospitalized in a neonatal intensive care unit. Neonatal Network, 15(3): 45-52, apr., 1996.

MINAYO, M. C. (Org.). Pesquisa social. teoria, método e criatividade. Petrópolis: Rio de Janeiro: Vozes,1997.

M I URA, E. Causas de mortalidade perinatal. In: M I URA, E. (Org.). Neonatologia. Principios e prática. Porto Alegre: Artes Médicas, 1991. p. 7-8.
PAPALIA, D.; OLDS, S. Desenvolvimento psicossocial na adolescência. In: PAPALIA, D.; OLDS, S. Desenvolvimento humano. Porto Alegre: Artes Médicas Sul, 2000. p.351-354.

RAMOS, M.; STEIN, L. Desenvolvimento do comportamento alimentar infantil. Jornal de Pediatria, 76(3): S229-S236, 2000.

SPITZ, R. A. O primeiro ano de vida. $7^{\mathrm{a}}$ ed. São Paulo: Martins Fontes, 1996. p. 279.

VAZ, F.A.C. (Coord.). Cuidados ao recém-nascido normal e patológico. São Paulo: Sarvier, 1989.

VIÇOSA, G. R. A interação mãe-bebê na maternidade precoce. In: FICHTNER, N. Prevenção, diagnóstico e tratamento dos transtornos mentais da infancia e da adolescência. Porto Alegre: Artes Médicas, 1997. p.36-4s.

WINNICOTT, D.W. Os bebês e suas mães. São Paulo: Martins Fontes, 1999. p.20^s.

WIRTH, A. F. Aplicação do método de observação de bebês em uma UTI Neonatal. In: CARON, N. A. (Org.). A relação pais-behês, da observação à clinica. São Paulo: Casa do Psicólogo, 2000. p.207232.

XAVIER, C. Assistência à alimentacão de bebês hospitalizados. In: BASSETO, M. C.; BROCK, R.; WAJNSTEJN, R. Neonatologia. Um convite à atuaçãofonoaudiológica. São Paulo: Ed. Lovise, 1998. p.255-275.

Recebido em 05/01/2002

Modificado em 25/01/2002 Aprovado em 30/01/2002 